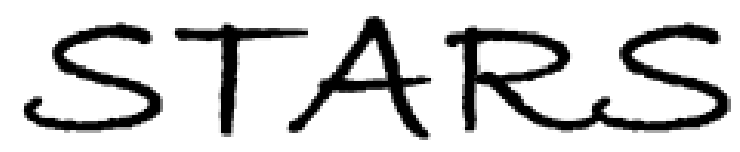

University of Central Florida

STARS

$1-1-2011$

\title{
Femtosecond laser induced photochemistry in materials tailored with photosensitive agents Invited
}

Arnaud Royon

Yannick Petit

Gautier Papon

Martin Richardson

University of Central Florida

Lionel Canioni

Find similar works at: https://stars.library.ucf.edu/facultybib2010

University of Central Florida Libraries http://library.ucf.edu

This Article is brought to you for free and open access by the Faculty Bibliography at STARS. It has been accepted for inclusion in Faculty Bibliography 2010 s by an authorized administrator of STARS. For more information, please contact STARS@ucf.edu.

\section{Recommended Citation}

Royon, Arnaud; Petit, Yannick; Papon, Gautier; Richardson, Martin; and Canioni, Lionel, "Femtosecond laser induced photochemistry in materials tailored with photosensitive agents Invited" (2011). Faculty Bibliography 2010s. 1831.

https://stars.library.ucf.edu/facultybib2010/1831

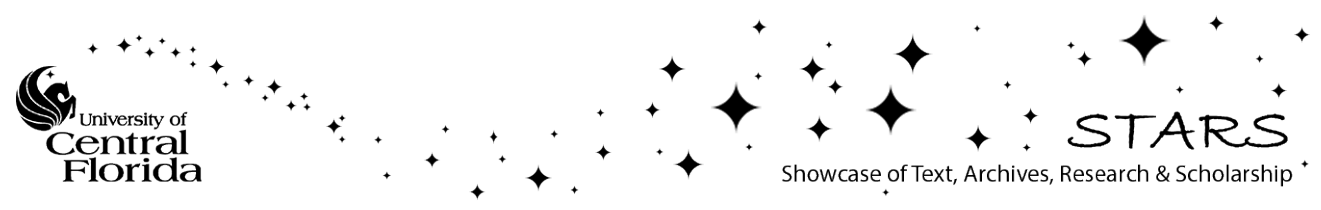




\title{
Femtosecond laser induced photochemistry in materials tailored with photosensitive agents [Invited]
}

\author{
Arnaud Royon, ${ }^{1, *}$ Yannick Petit, ${ }^{1,2}$ Gautier Papon, ${ }^{1}$ Martin Richardson, ${ }^{3}$ and Lionel \\ Canioni $^{1}$ \\ ${ }^{1}$ Laboratoire Ondes et Matière d'Aquitaine, CNRS, Université de Bordeaux, 351 Cours de la Libération, 33405 \\ Talence cedex, France \\ ${ }^{2}$ Institut de Chimie et de la Matière Condensée de Bordeaux, CNRS, Université de Bordeaux, 87 Avenue du Docteur \\ Schweitzer, 33608 Pessac cedex, France \\ ${ }^{3}$ College of Optics and Photonics/CREOL, University of Central Florida, 4000 Central Florida Boulevard, Orlando, \\ Florida 32816, USA \\ *a.royon@loma.u-bordeauxl.fr
}

\begin{abstract}
This article deals with the recent advances in photochemistry in optical materials induced by femtosecond laser pulses. The field of investigation of this paper is limited to bulk solid isotropic transparent materials (glasses and polymers), specifically tailored with photoactive agents. The formation mechanisms of laser-induced color centers, nanoclusters, nanoparticles and nanocrystallites are reviewed and argued, in particular the influence of the temperature during or after the laser irradiation. The relation between the photo-induced structures and the optical property modifications are discussed, as well as some applications.
\end{abstract}

(C)2011 Optical Society of America

OCIS codes: (160.4670) Optical materials; (140.3390) Laser materials processing; (140.3450) Laser induced chemistry; (320.2250) Femtosecond phenomena.

\section{References and links}

1. R. R. Gattass and E. Mazur, "Femtosecond laser micromachining in transparent materials," Nat. Photonics 2(4), 219-225 (2008).

2. M. Ams, G. D. Marshall, P. Dekker, J. A. Piper, and M. J. Withford, "Ultrafast laser written active devices," Laser Photonics Rev. 3(6), 535-544 (2009).

3. Y.-L. Zhang, Q.-D. Chen, H. Xia, and H.-B. Sun, "Designable 3D nanofabrication by femtosecond laser direct writing," Nano Today 5(5), 435-448 (2010).

4. K. M. Davis, K. Miura, N. Sugimoto, and K. Hirao, "Writing waveguides in glass with a femtosecond laser," Opt. Lett. 21(21), 1729-1731 (1996).

5. M. Ams, G. D. Marshall, P. Dekker, M. Dubov, V. K. Mezentsev, I. Bennion, and M. J. Withford, "Investigation of ultrafast laser-photonic material interactions: challenges for directly written glass photonics," IEEE J. Sel. Top. Quantum Electron. 14(5), 1370-1381 (2008).

6. L. Sudrie, M. Franco, B. Prade, and A. Mysyrowicz, "Study of damage in fused silica induced by ultra-short IR laser pulses," Opt. Commun. 191(3-6), 333-339 (2001).

7. K. Hirao and K. Miura, "Writing waveguides and gratings in silica and related materials by a femtosecond laser," J. Non-Cryst. Sol. 239, 91-95 (1998).

8. D. Homoelle, S. Wielandy, A. L. Gaeta, N. F. Borrelli, and C. Smith, "Infrared photosensitivity in silica glasses exposed to femtosecond laser pulses," Opt. Lett. 24(18), 1311-1313 (1999).

9. Y. Shimotsuma, P. G. Kazansky, J. Qiu, and K. Hirao, "Self-organized nanogratings in glass irradiated by ultrashort light pulses," Phys. Rev. Lett. 91(24), 247405 (2003).

10. L. A. Fernandes, J. R. Grenier, J. H. Kim, P. R. Herman, J. S. Aitchison, and P. V. Marques, "Femtosecond laser direct fabrication of integrated optical wave plates in fused silica," in CLEO:2011 - Laser Applications to Photonic Applications, OSA Technical Digest (CD) (Optical Society of America, 2011), paper CWO6.

11. J. D. Mills, P. G. Kazansky, E. Bricchi, and J. J. Baumberg, "Embedded anisotropic microreflectors by femtosecond-laser nanomachining," Appl. Phys. Lett. 81(2), 196-198 (2002).

12. E. N. Glezer, M. Milosavljevic, L. Huang, R. J. Finlay, T.-H. Her, J. P. Callan, and E. Mazur, "Threedimensional optical storage inside transparent materials," Opt. Lett. 21(24), 2023-2025 (1996).

13. H.-B. Sun, Y. Xu, S. Matsuo, and H. Misawa, "Microfabrication and characteristics of two-dimensional photonic crystal structures in vitreous silica," Opt. Rev. 6(5), 396-398 (1999).

14. L. Siiman, J. Lumeau, and L. B. Glebov, "Nonlinear photosensitivity of photo-thermo-refractive glass by high intensity laser irradiation," J. Non-Cryst. Sol. 354, 4070-4074 (2008). 
15. A. Podlipensky, A. Abdolvand, G. Seifert, and H. Graener, "Femtosecond laser assisted production of dichroitic 3D structures in composite glass containing Ag nanoparticles," Appl. Phys., A Mater. Sci. Process. 80(8), 16471652 (2005).

16. P. Zijlstra, J. W. M. Chon, and M. Gu, "Five-dimensional optical recording mediated by surface plasmons in gold nanorods," Nature 459(7245), 410-413 (2009).

17. M. Bellec, A. Royon, B. Bousquet, K. Bourhis, M. Treguer, T. Cardinal, M. Richardson, and L. Canioni, "Beat the diffraction limit in 3D direct laser writing in photosensitive glass," Opt. Express 17(12), 10304-10318 (2009).

18. G. De Cremer and B. F. Sels, J.-I. Hotta, M. B. J. Roeffaers, E. Bartholomeeusen, E. Coutino-Gonzales, V. Valtchev, D. E. De Vos, T. Vosch, and J. Hofkens, "Optical encoding of silver zeolite microcarriers," Adv. Mater. (Deerfield Beach Fla.) 22, 957-960 (2010).

19. A. Royon, K. Bourhis, M. Bellec, G. Papon, B. Bousquet, Y. Deshayes, T. Cardinal, and L. Canioni, "Silver clusters embedded in glass as a perennial high capacity optical recording medium," Adv. Mater. (Deerfield Beach Fla.) 22(46), 5282-5286 (2010).

20. K. Miura, J. Qiu, T. Mitsuyu, and K. Hirao, "Space-selective growth of frequency-conversion crystals in glasses with ultrashort infrared laser pulses," Opt. Lett. 25(6), 408-410 (2000).

21. A. Podlipensky, J. Lange, G. Seifert, H. Graener, and I. Cravetchi, "Second-harmonic generation from ellipsoidal silver nanoparticles embedded in silica glass," Opt. Lett. 28(9), 716-718 (2003).

22. Y. Dai, B. Zhu, J. Qiu, H. Ma, B. Lu, and B. Yu, "Space-selective precipitation of functional crystals in glass by using a high repetition rate femtosecond laser," Chem. Phys. Lett. 443(4-6), 253-257 (2007).

23. L. Canioni, M. Bellec, A. Royon, B. Bousquet, and T. Cardinal, "Three-dimensional optical data storage using third-harmonic generation in silver zinc phosphate glass," Opt. Lett. 33(4), 360-362 (2008).

24. J. Choi, M. Bellec, K. Bourhis, A. Royon, L. Canioni, T. Cardinal, E. Fargin, V. Rodriguez, M. Dussauze, A. Delestre, and M. Richardson, "Femtosecond laser induced micro-structured silver containing glass as an engineered nonlinear optical material," in Advances in Optical Materials, OSA Technical Digest (CD) (Optical Society of America, 2009), paper AWB3.

25. A. Royon, M. Bellec, J. Y. Choi, K. Bourhis, T. Cardinal, M. Richardson, and L. Canioni, "Second-harmonic generation by direct-laser-induced-poling in a femto-photo-luminescent glass," in Bragg Gratings, Photosensitivity, and Poling in Glass Waveguides, OSA Technical Digest (CD) (Optical Society of America, 2010), paper BThD2.

26. S. D. Stookey, "Photosensitive glass," Ind. Eng. Chem. 41(4), 856-861 (1949).

27. Y. Kondo, K. Miura, T. Suzuki, H. Inouye, T. Mitsuyu, and K. Hirao, "Three-dimensional arrays of crystallites within glass by using non-resonant femtosecond pulses,” J. Non-Cryst. Sol. 253, 143-156 (1999).

28. A. V. Podlipensky, V. Grebenev, G. Seifert, and H. Graener, "Ionization and photomodification of Ag nanoparticles in soda-lime glass by 150 fs laser irradiation: a luminescence study," J. Lumin. 109, 135-142 (2004).

29. B. Hua, Y. Shimotsuma, M. Nishi, K. Miura, and K. Hirao, "Micro-modification of metal-doped glasses by a femtosecond laser," J. Laser Micro/Nanoengineering 2, 36-39 (2007).

30. J. Qiu, X. Jiang, C. Zhu, H. Inouye, J. Si, and K. Hirao, "Optical properties of structurally modified glasses doped with gold ions," Opt. Lett. 29(4), 370-372 (2004).

31. Y. Cheng, K. Sugioka, M. Masuda, K. Shihoyama, K. Toyoda, and K. Midorikawa, "Optical gratings embedded in photosensitive glass by photochemical reaction using a femtosecond laser," Opt. Express 11(15), 1809-1816 (2003).

32. M. Masuda, K. Sugioka, Y. Cheng, N. Aoki, M. Kawachi, K. Shihoyama, K. Toyoda, H. Helvajian, and K. Midorikawa, "3-D microstructuring inside photosensitive glass by femtosecond laser excitation," Appl. Phys., A Mater. Sci. Process. 76(5), 857-860 (2003).

33. Y. Shimotsuma, M. Sakakura, K. Miura, J. Qiu, P. G. Kazansky, K. Fujita, and K. Hirao, "Application of femtosecond-laser induced nanostructures in optical memory,” J. Nanosci. Nanotechnol. 7(1), 94-104 (2007).

34. J. Qiu, P. G. Kazanski, J. Si, K. Miura, T. Mitsuyu, K. Hirao, and A. L. Gaeta, "Memorized polarizationdependent light scattering in rare-earth-ion-doped glass," Appl. Phys. Lett. 77(13), 1940-1942 (2000).

35. J. Qiu, K. Miura, and K. Hirao, "Femtosecond laser-induced microfeatures in glasses and their applications," J. Non-Cryst. Sol. 354, 1100-1111 (2008).

36. Y. Watanabe, G. Namikawa, T. Onuki, K. Nishio, and T. Tsuchiya, "Photosensitivity in phosphate glass doped with $\mathrm{Ag}^{+}$upon exposure to near-ultraviolet femtosecond laser pulses," Appl. Phys. Lett. 78(15), 2125-2127 (2001).

37. T. Kurobori, W. Zheng, and C. Zhao, "Silver-activated radiophotoluminescent glass: band assignments and a novel readout system using a modulated UV laser diode," 11th Europhysical Conference on Defects in Insulating Materials (2010).

38. Y. Miyamoto, T. Yamamoto, K. Kinoshita, S. Koyama, Y. Takei, H. Nanto, Y. Shimotsuma, M. Sakakura, K. Miura, and K. Hirao, "Emission mechanism of radiophotoluminescence in Ag-doped phosphate glass," Radiat. Meas. 45(3-6), 546-549 (2010).

39. Y. Miyamoto, K. Kinoshita, S. Koyama, Y. Takei, H. Nanto, T. Yamamoto, M. Sakakura, Y. Shimotsuma, K. Miura, and K. Hirao, "Emission and excitation mechanism of radiophotoluminescence in $\mathrm{Ag}^{+}$-activated phosphate glass," Nucl. Instrum. Methods Phys. Res. A 619(1-3), 71-74 (2010).

40. W. Zheng and T. Kurobori, "Assignments and optical properties of X-ray-induced colour centres in blue and orange radiophotoluminescent silver-activated glasses," J. Lumin. 131(1), 36-40 (2011). 
41. W. Zheng, T. Kurobori, Y. Miyamoto, H. Nanto, and T. Yamamoto, "Formation and assignment of silver defect centres in phosphate glass induced by femtosecond laser pulses," Radiat. Meas. 1-4, (2011), doi:10.1016/j.radmeas.2011.01.004.

42. C. Maurel, T. Cardinal, M. Bellec, L. Canioni, B. Bousquet, M. Treguer, J.-J. Videau, J. Choi, and M. Richardson, "Luminescence properties of silver zinc phosphate glasses following different irradiations," J. Lumin. 129(12), 1514-1518 (2009).

43. K. Bourhis, A. Royon, M. Bellec, J. Choi, A. Fargues, M. Treguer, J.-J. Videau, D. Talaga, M. Richardson, T. Cardinal, and L. Canioni, "Femtosecond laser structuring and optical properties of a silver-containing glass," J. Non-Cryst. Solids 356, 2658-2665 (2010).

44. M. Bellec, A. Royon, K. Bourhis, J. Choi, B. Bousquet, M. Treguer, T. Cardinal, J.-J. Videau, M. Richardson, and L. Canioni, "3D patterning at the nanoscale of fluorescent emitters in glass," J. Phys. Chem. C 114(37), $15584-15588$ (2010).

45. T. Gleitsmann, B. Stegemann, and T. M. Bernhardt, "Femtosecond-laser-activated fluorescence from silver oxide nanoparticles," Appl. Phys. Lett. 84(20), 4050-4052 (2004).

46. T. Gleitsmann, T. M. Bernhardt, and L. Wöste, "Luminescence properties of femtosecond-laser-activated silver oxide nanoparticles embedded in a biopolymer matrix," Appl. Phys., A Mater. Sci. Process. 82(1), 125-130 (2006).

47. G. De Cremer, Y. Antoku, M. B. J. Roeffaers, M. Sliwa, J. Van Noyen, S. Smout, J. Hofkens, D. E. De Vos, B. F. Sels, and T. Vosch, "Photoactivation of silver-exchanged zeolite A," Angew. Chem. Int. Ed. Engl. 47(15), 2813-2816 (2008).

48. G. De Cremer, E. Coutiño-Gonzalez, M. B. J. Roeffaers, B. Moens, J. Ollevier, M. Van der Auweraer, R. Schoonheydt, P. A. Jacobs, F. C. De Schryver, J. Hofkens, D. E. De Vos, B. F. Sels, and T. Vosch, "Characterization of fluorescence in heat-treated silver-exchanged zeolites," J. Am. Chem. Soc. 131(8), 30493056 (2009).

49. G. De Cremer, E. Coutiño-Gonzalez, M. B. J. Roeffaers, D. E. De Vos, J. Hofkens, T. Vosch, and B. F. Sels, "In situ observation of the emission characteristics of zeolite-hosted silver species during heat treatment," ChemPhysChem 11(8), 1627-1631 (2010).

50. Y. Cheng, K. Sugioka, K. Midorikawa, M. Masuda, K. Toyoda, M. Kawachi, and K. Shihoyama, "Threedimensional micro-optical components embedded in photosensitive glass by a femtosecond laser," Opt. Lett. 28(13), 1144-1146 (2003).

51. J. Qiu, K. Miura, T. Suzuki, T. Mitsuyu, and K. Hirao, "Permanent photoreduction of Sm ${ }^{3+}$ to $\mathrm{Sm}^{2+}$ inside a sodium aluminoborate glass by an infrared femtosecond pulsed laser," Appl. Phys. Lett. 74(1), 10-12 (1999).

52. Y. Liu, M. Shimizu, B. Zhu, Y. Dai, B. Qian, J. Qiu, Y. Shimotsuma, K. Miura, and K. Hirao, "Micromodification of element distribution in glass using femtosecond laser irradiation," Opt. Lett. 34(2), 136138 (2009).

53. A. Unal, A. Stalmashonak, G. Seifert, and H. Graener, "Ultrafast dynamics of silver nanoparticle shape transformation studied by femtosecond pulse-pair irradiation," Phys. Rev. B 79(11), 115411 (2009).

54. A. Unal, A. Stalmashonak, G. Seifert, and H. Graener, "Time-resolved investigation of laser-induced shape transformation of silver nanoparticles," Phys. Rev. B 80(11), 115415 (2009).

55. G. Seifert, M. Kaempfe, K.-J. Berg, and H. Graener, "Femtosecond pump-probe investigation of ultrafast silver nanoparticle deformation in a glass matrix," Appl. Phys. B 71, 795-800 (2000).

56. A. Stalmashonak, A. Podlipensky, G. Seifert, and H. Graener, "Intensity-driven, laser induced transformation of Ag nanospheres to anisotropic shapes," Appl. Phys. B 94(3), 459-465 (2009).

57. C. B. Schaffer, A. Brodeur, and E. Mazur, "Laser-induced breakdown and damage in bulk transparent materials induced by tightly focused femtosecond laser pulses," Meas. Sci. Technol. 12(11), 1784-1794 (2001).

58. B. C. Stuart, M. D. Feit, S. Herman, A. M. Rubenchik, B. W. Shore, and M. D. Perry, "Nanosecond-tofemtosecond laser-induced breakdown in dielectrics," Phys. Rev. B Condens. Matter 53(4), 1749-1761 (1996).

59. S. S. Mao, F. Quéré, S. Guizard, X. Mao, R. E. Russo, G. Petite, and P. Martin, "Dynamics of femtosecond laser interactions with dielectrics," Appl. Phys., A Mater. Sci. Process. 79, 1695-1709 (2004).

60. K. Miura, J. Qiu, H. Inouye, T. Mitsuyu, and K. Hirao, "Photowritten optical waveguides in various glasses with ultrashort pulse laser," Appl. Phys. Lett. 71(23), 3329-3331 (1997).

61. S. Juodkazis, K. Nishimura, S. Tanaka, H. Misawa, E. G. Gamaly, B. Luther-Davies, L. Hallo, P. Nicolai, and V. T. Tikhonchuk, "Laser-induced microexplosion confined in the bulk of a sapphire crystal: evidence of multimegabar pressures,” Phys. Rev. Lett. 96(16), 166101 (2006).

62. P. P. Rajeev, M. Gertsvolf, E. Simova, C. Hnatovsky, R. S. Taylor, V. R. Bhardwaj, D. M. Rayner, and P. B. Corkum, "Memory in nonlinear ionization of transparent solids," Phys. Rev. Lett. 97(25), 253001 (2006).

63. R. Taylor, C. Hnatovsky, and E. Simova, "Applications of femtosecond laser induced self-organized planar nanocracks inside fused silica glass," Laser Photonics Rev. 2(1-2), 26-46 (2008).

64. L. V. Keldysh, "Ionization in the field of a strong electromagnetic wave," Sov. Phys. JETP 20, 1307-1314 (1965).

65. L. N. Gaier, M. Lein, M. I. Stockman, G. L. Yudin, P. B. Corkum, M. Y. Ivanov, and P. L. Knight, "Holeassisted energy deposition in dielectrics and clusters in the multiphoton regime," J. Mod. Opt. 52(7), 1019-1030 (2005).

66. L. N. Gaier, M. Lein, M. I. Stockman, P. L. Knight, P. B. Corkum, M. Y. Ivanov, and G. L. Yudin, "Ultrafast multiphoton forest fires and fractals in clusters and dielectrics," J. Phys. At. Mol. Opt. Phys. 37(3), L57-L67 (2004).

67. D. M. Rayner, A. Naumov, and P. B. Corkum, "Ultrashort pulse non-linear optical absorption in transparent media," Opt. Express 13(9), 3208-3217 (2005). 
68. C. B. Schaffer, J. F. Garcia, and E. Mazur, "Bulk heating of transparent materials using a high-repetition-rate femtosecond laser," Appl. Phys., A Mater. Sci. Process. 76(3), 351-354 (2003).

69. S. M. Eaton, H. Zhang, P. R. Herman, F. Yoshino, L. Shah, J. Bovatsek, and A. Y. Arai, "Heat accumulation effects in femtosecond laser-written waveguides with variable repetition rate," Opt. Express 13(12), 4708-4716 (2005).

70. R. R. Gattass, L. R. Cerami, and E. Mazur, "Micromachining of bulk glass with bursts of femtosecond laser pulses at variable repetition rates," Opt. Express 14(12), 5279-5284 (2006).

71. M. Sakakura, M. Terazima, Y. Shimotsuma, K. Miura, and K. Hirao, "Heating and rapid cooling of bulk glass after photoexcitation by a focused femtosecond laser pulse," Opt. Express 15(25), 16800-16807 (2007).

72. M. Sakakura, M. Shimizu, Y. Shimotsuma, K. Miura, and K. Hirao, "Temperature distribution and modification mechanism inside glass with heat accumulation during $250 \mathrm{kHz}$ irradiation of femtosecond laser pulses," Appl. Phys. Lett. 93(23), 231112 (2008).

73. M. Shimizu, M. Sakakura, M. Ohnishi, Y. Shimotsuma, T. Nakaya, K. Miura, and K. Hirao, "Mechanism of heat-modification inside a glass after irradiation with high-repetition rate femtosecond laser pulses," J. Appl. Phys. 108(7), 073533 (2010).

74. M. Martin, J. J. Videau, L. Canioni, F. Adamietz, L. Sarger, and G. Le Flem, "Planar waveguides formed by $\mathrm{Ag}^{+}-$ $\mathrm{Na}^{+}$ion exchange in nonlinear optical glasses: diffusion and optical properties," Appl. Opt. 39(3), 435-440 (2000).

75. S. Kanehira, K. Miura, and K. Hirao, "Ion exchange in glass using femtosecond laser irradiation," Appl. Phys. Lett. 93(2), 023112 (2008).

76. Y. Dai, G. Yu, M. He, H. Ma, X. Yan, and G. Ma, "High repetition rate femtosecond laser irradiation-induced elements redistribution in Ag-doped glass," Appl. Phys. B 103(3), 663-667 (2011).

77. J. E. Shelby, Introduction to Glass Science, 2nd ed., (Royal Society of Chemistry, 2005).

78. S. Coffa, J. M. Poate, D. C. Jacobson, W. Frank, and W. Gustin, "Determination of diffusion mechanisms in amorphous silicon," Phys. Rev. B Condens. Matter 45(15), 8355-8358 (1992).

79. V. V. Temnov, K. Sokolowski-Tinten, P. Zhou, A. El-Khamhawy, and D. von der Linde, "Multiphoton ionization in dielectrics: comparison of circular and linear polarization," Phys. Rev. Lett. 97(23), 237403 (2006).

80. M. Ams, G. D. Marshall, and M. J. Withford, "Study of the influence of femtosecond laser polarisation on direct writing of waveguides," Opt. Express 14(26), 13158-13163 (2006).

81. A. Ferrer, A. Ruiz de la Cruz, D. Puerto, W. Gawelda, J. A. Vallés, M. A. Rebolledo, V. Berdejo, J. Siegel, and J. Solis, "In situ assessment and minimization of nonlinear propagation effects for femtosecond-laser waveguide writing in dielectrics," J. Opt. Soc. Am. B 27(8), 1688-1692 (2010).

82. A. Stalmashonak, H. Graener, and G. Seifert, "Transformation of silver nanospheres embedded in glass to nanodisks using circularly polarized femtosecond pulses," Appl. Phys. Lett. 94(19), 193111 (2009).

83. V. R. Bhardwaj, E. Simova, P. P. Rajeev, C. Hnatovsky, R. S. Taylor, D. M. Rayner, and P. B. Corkum, "Optically produced arrays of planar nanostructures inside fused silica," Phys. Rev. Lett. 96(5), 057404 (2006).

84. J. Squier and J. Muller, "High resolution nonlinear microscopy: A review of sources and methods for achieving optical imaging," Rev. Sci. Instrum. 72(7), 2855-2867 (2001).

85. J. B. Ashcom, R. R. Gattass, C. B. Schaffer, and E. Mazur, "Numerical aperture dependence of damage and supercontinuum generation from femtosecond laser pulses in bulk fused silica," J. Opt. Soc. Am. B 23(11), 2317-2322 (2006).

86. J. Qiu, C. Zhu, T. Nakaya, J. Si, K. Kojima, F. Ogura, and K. Hirao, "Space-selective valence state manipulation of transition metal ions inside glasses by a femtosecond laser," Appl. Phys. Lett. 79(22), 3567-3569 (2001).

87. I. Díez and R. H. A. Ras, "Fluorescent silver nanoclusters," Nanoscale 3(5), 1963-1970 (2011).

88. M. Kaempfe, G. Seifert, K.-J. Berg, H. Hofmeister, and H. Graener, "Polarization dependence of the permanent deformation of silver nanoparticles in glass by ultrashort laser pulses," Eur. Phys. J. D 16(1), 237-240 (2001).

89. Y. Dai, X. Hu, C. Wang, D. Chen, X. Jiang, C. Zhu, B. Yu, and J. Qiu, "Fluorescent Ag nanoclusters in glass induced by an infrared femtosecond laser," Chem. Phys. Lett. 439(1-3), 81-84 (2007).

90. S. Lee, K.-S. Jang, J.-H. Shin, M.-T. Trinh, K.-S. Lim, I.-B. Sohn, Y.-C. Noh, J. Lee, and E. Kim, "Spectral change in silver-doped sodium-borate glass by using femtosecond laser irradiation," J. Korean Phys. Soc. 52(5), $1665-1668$ (2008).

91. Q.-Z. Zhao, J.-R. Qiu, X.-W. Jiang, C.-J. Zhao, and C.-S. Zhu, "Controllable precipitation and dissolution of silver nanoparticles in ultrafast laser pulses irradiated $\mathrm{Ag}^{+}$-doped phosphate glass," Opt. Express 12(17), 40354040 (2004).

92. Y. Dai, J. Qiu, X. Hu, L. Yang, X. Jiang, C. Zhu, and B. Yu, "Effect of cerium oxide on the precipitation of silver nanoparticles in femtosecond laser irradiated silicate glass," Appl. Phys. B 84(3), 501-505 (2006).

93. J. Qiu, M. Shirai, T. Nakaya, J. Si, X. Jiang, C. Zhu, and K. Hirao, "Space-selective precipitation of metal nanoparticles inside glasses," Appl. Phys. Lett. 81(16), 3040-3042 (2002).

94. S. Qu, J. Qiu, C. Zhao, X. Jiang, H. Zeng, C. Zhu, and K. Hirao, "Metal nanoparticles precipitation in periodic arrays in $\mathrm{Au}_{2} \mathrm{O}$-doped glass by two interfered femtosecond laser pulses," Appl. Phys. Lett. 84(12), 2046-2048 (2004).

95. J. Qiu, X. Jiang, C. Zhu, M. Shirai, J. Si, N. Jiang, and K. Hirao, "Manipulation of gold nanoparticles inside transparent materials," Angew. Chem. Int. Ed. Engl. 43(17), 2230-2234 (2004).

96. X. Hu, Q. Zhao, X. Jiang, C. Zhu, and J. Qiu, "Space-selective co-precipitation of silver and gold nanoparticles in femtosecond laser pulses irradiated $\mathrm{Ag}^{+}, \mathrm{Au}^{3+}$ co-doped silicate glass," Solid State Commun. 138(1), 43-46 (2006).

97. H. Zeng, J. Qiu, X. Jiang, C. Zhu, and F. Gan, "Effect of $\mathrm{Al}_{2} \mathrm{O}_{3}$ on the precipitation of $\mathrm{Ag}$ nanoparticles in silicate glasses," J. Cryst. Growth 262(1-4), 255-258 (2004). 
98. A. Stalmashonak, G. Seifert, and H. Graener, "Optical three-dimensional shape analysis of metallic nanoparticles after laser-induced deformation," Opt. Lett. 32(21), 3215 (2007).

99. A. Stalmashonak, G. Seifert, and H. Graener, "Spectral range extension of laser-induced dichroism in composite glass with silver nanoparticles," J. Opt. A, Pure Appl. Opt. 11(6), 065001 (2009).

100.G. Seifert, A. Stalmashonak, H. Hofmeister, J. Haug, and M. Dubiel, "Laser-induced, polarization dependent shape transformation of Au/Ag nanoparticles in glass," Nanoscale Res. Lett. 4(11), 1380-1383 (2009).

101.A. Stalmashonak, G. Seifert, A. A. Unal, U. Skrzypczak, A. Podlipensky, A. Abdolvand, and H. Graener, "Towards the production of micro-polarizers by irradiation of composite glasses with silver nanoparticles," Appl. Opt. 48(25), F37-F43 (2009).

102.M. Kaempfe, T. Rainer, K.-J. Berg, G. Seifert, and H. Graener, "Ultrashort laser pulse induced deformation of silver nanoparticles in glass," Appl. Phys. Lett. 74(9), 1200-1202 (1999).

103.M. Kaempfe, H. Hofmeister, S. Hopfe, G. Seifert, and H. Graener, "Morphological Changes of Silver Nanoparticle Distributions in Glass Induced by Ultrashort Laser Pulses," J. Phys. Chem. B 104(50), 11847$11852(2000)$

104.G. Seifert, M. Kaempfe, K.-J. Berg, and H. Graener, "Production of dichroitic diffraction gratings in glasses containing silver nanoparticles via particle deformation with ultrashort laser pulses," Appl. Phys. B 73(4), 355359 (2001).

105.A. Stalmashonak, A. A. Unal, H. Graener, and G. Seifert, "Effects of temperature on laser-induced shape modification of silver nanoparticles embedded in glass," J. Phys. Chem. C 113(28), 12028-12032 (2009).

106.B. Fisette, F. Busque, J.-Y. Degorce, and M. Meunier, "Three-dimensional crystallization inside photosensitive glasses by focused femtosecond laser," Appl. Phys. Lett. 88(9), 091104 (2006).

107.Y. Liu, B. Zhu, Y. Dai, X. Qiao, S. Ye, Y. Teng, Q. Guo, H. Ma, X. Fan, and J. Qiu, "Femtosecond laser writing of $\mathrm{Er}^{3+}$-doped $\mathrm{CaF}_{2}$ crystalline patterns in glass," Opt. Lett. 34(21), 3433-3435 (2009).

108.L. Siiman, J. Lumeau, and L. B. Glebov, "Nonlinear photoionization and laser-induced damage in silicate glasses by infrared ultrashort laser pulses," Appl. Phys. B 96(1), 127-134 (2009).

109. Y. Yonesaki, K. Miura, R. Araki, K. Fujita, and K. Hirao, "Space-selective precipitation of non-linear optical crystals inside silicate glasses using near-infrared femtosecond laser," J. Non-Cryst. Sol. 351, 885-892 (2005).

\section{Introduction}

Focused femtosecond (fs) pulses with energies of a few hundreds of nanojoules have become a key tool to modify the physical properties of materials in three dimensions (3D). Because of the nonlinear behavior of the interaction, the energy deposited by a focused fs pulse is confined inside the focal volume, resulting in sub-micrometer spatial resolution for local structuring, as illustrated in Fig. 1. This well established technology has applications in many fields, ranging from the technologies of information and telecommunications, medicine, biology, etc... [1-3]. Among all the physical properties susceptible to be modified, the refractive index (RI) is the easiest and historically the first that has been investigated for waveguide fabrication [4].

Depending on the application in view and for a given material, the irradiation conditions must be optimized. For example fused silica, which is considered as a model glass, exhibits no less than three different response regimes when increasing the pulse energy density (or fluence) (cf. Fig. 2(b)) [5]. At low fluence (type 1), the RI change is isotropic [6], enabling the fabrication of waveguides [4], gratings [7] and couplers [8]. At intermediate fluences (type 2), the RI change is anisotropic [6] due to the presence of "nanogratings" [9], enabling the fabrication of polarization control devices [10] and micro-reflectors [11]. At high fluence (type 3), micro-cavities with a low RI core and a high RI shell are formed [12] enabling the fabrication of optical memories [12] and photonic crystals [13]. 
a)

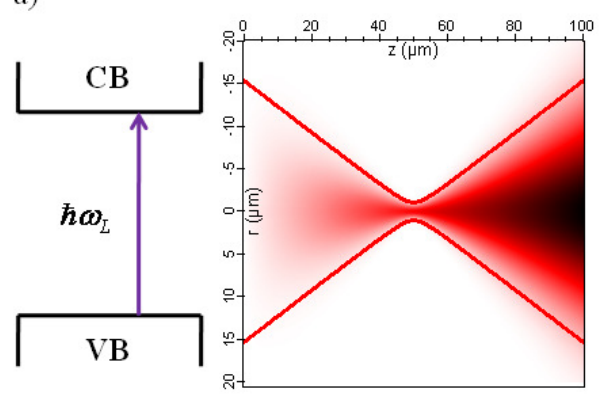

b)

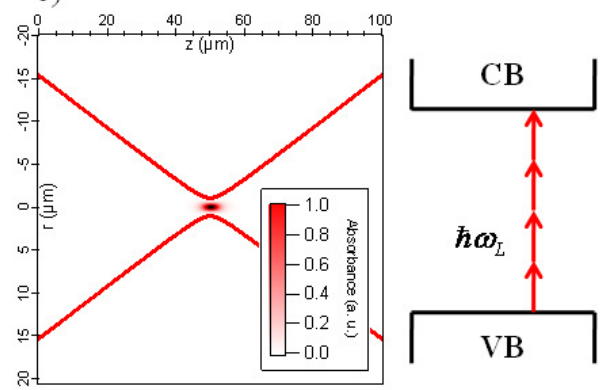

Fig. 1. Linear absorption (a) and four-photon absorption (b) of a Gaussian beam focused with a 0.5-numerical aperture microscope objective inside a random material. In the case of multiphoton absorption, the laser energy is absorbed inside the focal volume.

Fused silica has been by far the most studied of all the materials. Nevertheless, even if its study is interesting from a fundamental point of view, this material is not the best suited for most of the applications cited above. Actually, to improve the applications, the irradiation conditions as well as the intrinsic properties of the material must be optimized to exhibit the specific and desired response to fs laser exposure.

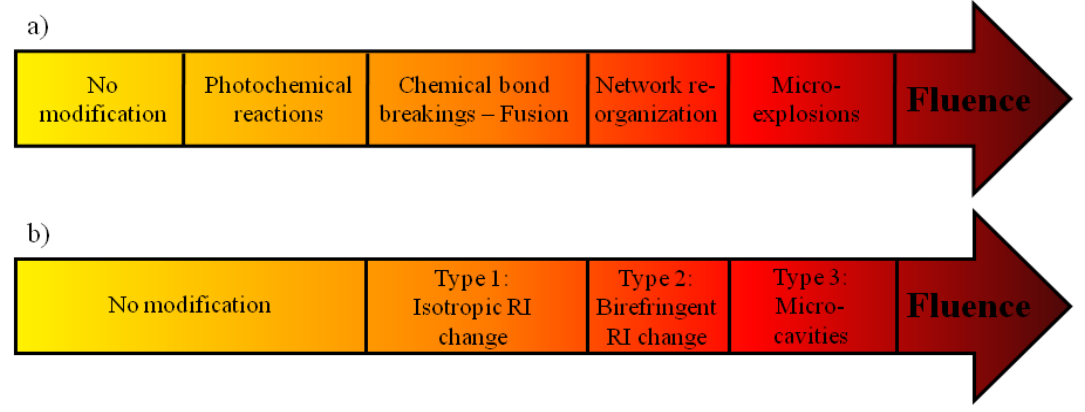

Fig. 2. Fluence scale of the different response regimes of materials in general (a) and of fused silica in particular (b) exposed to femtosecond pulses. In the general case, when increasing the fluence, photochemical reactions are followed by chemical bond breakings and fusion, by network reorganization and finally by micro-explosions. In the specific case of fused silica, these phenomena correspond to first an isotropic RI change (type 1), then an anisotropic RI change (type 2), and finally to micro-cavities with a low RI core and a high RI shell (type 3).

Materials doped with metal nanoparticles (NPs) or photosensitive ions in different matrices are of particular interest. These materials can be specifically tailored to exhibit a strong variation in the RI [14] after laser irradiation and appropriate thermal treatment, and also appreciable changes in other optical properties, such as plasmon resonance absorption [15,16], luminescence [17-19] and optical nonlinearities [20-25]. Such materials can be specifically designed to optimize their response from the interaction with fs pulses and to minimize the energy budget necessary to induce modifications. Typically fluences of a few $\mathrm{J} . \mathrm{cm}^{-2}$ and irradiances of a few TW. $\mathrm{cm}^{-2}$ are sufficient, but not exclusively for photochemical reactions to occur ( $c f$. Fig. 2(a)), compatible with the output of simple laser oscillators.

Fs laser-induced photochemistry (LIP) has been reported in many homogeneous materials such as glasses, polymers and crystals. Indeed LIP has already been explored in a large variety of glass matrices, from self-elaborated or commercial glasses: Silicates [15,22,26-30], aluminosilicates [31-33] known as Foturan glasses, aluminates [34,35], borates [33], aluminoborates [20], and phosphates [17,19,23,36-44]. LIP has also been performed in polymer and crystal matrices, such as polymeric gelatins [45,46] and zeolites [18,47-49].

The laser-irradiated and structured materials can be either undoped [20], or doped with noble metal ions $\mathrm{Cu}^{2+}[26,29], \mathrm{Ag}^{+}[14,17,23,26,27,29,31,32,35,43,44,50]$ and $\mathrm{Au}^{+}[26,30]$, or 
other transition metal ions such as $\mathrm{Fe}^{3+}$ and $\mathrm{Mn}^{3+}$ [35] or $\mathrm{Ti}^{3+}$ [22], and also doped with rare earth ions such as $\mathrm{Sm}^{3+}[33,51], \mathrm{Eu}^{2+}[34]$ and $\mathrm{Eu}^{3+}[35,52]$.

These materials show an intrinsic response to intense laser irradiation. However, to improve laser/material interaction, some of these materials are prepared to obtain better laser modification through the use of thermoreducing agents such as tin or antinomy [26,32] or optical sensitizer ions such as $\mathrm{Ce}^{3+}[26,31,32,50]$, although $\mathrm{Ce}^{3+}$ ion is shown not to be always indispensable [14,27]. Sensitizer ions can contribute to providing enhanced reductive properties to reduce the valence state of photosensitive elements.

LIP has also been reported in composite materials made of bulk materials with embedded metallic particles, where the laser/material interaction can lead to a geometric reshaping of these particles from spherical to oblong shapes. These re-shaped particles provide modified structural and optical properties. Laser-induced particle deformation has been reported with gold nanorods in polymer [16], with silver NPs in silica glass [21] or in soda lime glasses $[15,28,53,54]$, with gold NPs $[55,56]$.

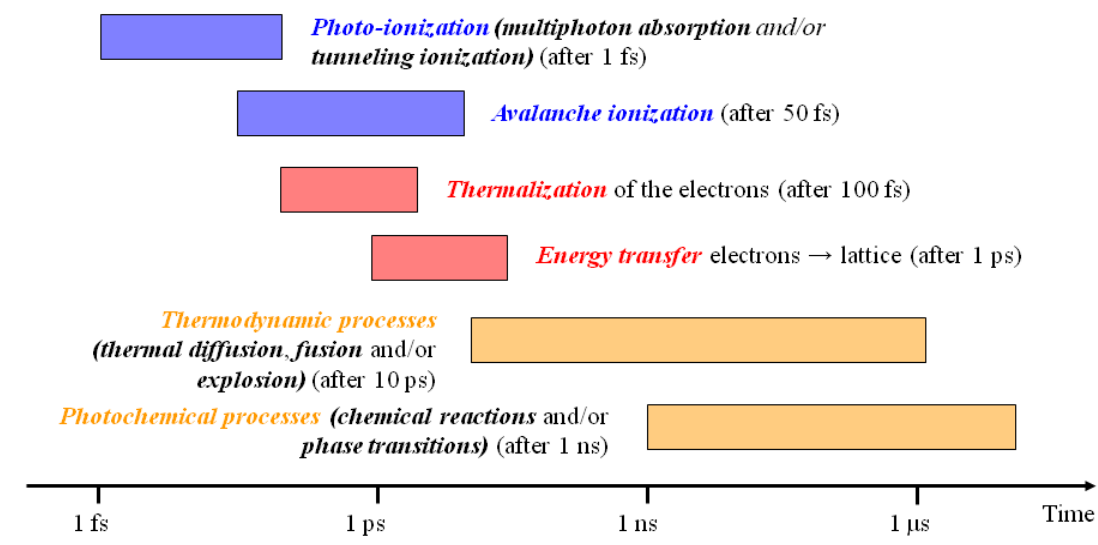

Fig. 3. Timescale of the physical phenomena involved in laser-material interaction.

Fs laser materials interaction is a field that has been extensively studied during the past decade. The understanding of the physical processes involved and their associated characteristic times is of particular importance [1,5,57-59]. Even though the picture is not completely clear and depends on the material properties and the irradiation regime, it is admitted in the community that, when a single high fluence fs laser pulse is incident onto a material, some of the following events occur ( $c f$. Fig. 3). Firstly, the laser energy is absorbed by the material and generates photoelectrons. These electrons then transfer their kinetic energy to the lattice. Finally, the heat diffuses, the material melts and fusion or explosion occur, responsible for type 1 and type 3 response regimes, respectively. Both these regimes can be accessed with a single pulse $[60,61]$, implying that the increased temperature induced is not critical to the resulting modifications. However for the type 2 regime to be induced, it seems that several pulses incident within a short period of time ( $\mu$ s's) are necessary for memory effects to take place during the interaction time [62]. For photochemical reactions to occur, control of the pulse after pulse accumulated heat through the multiple-pulse irradiation is even more important, since it will drive the diffusion of the chemical species inside the temperature gradient [44].

Previous reviews of fs laser-materials interactions [1-3,5,59,63] have concentrated mainly on usual materials, fused silica in particular, focusing on material modifications such as RI changes and void creations. However in this review we mainly focus on glass and polymer matrices doped with metal NPs or photosensitive ions that are processed by two steps: fs laser pulse exposure within the bulk and thermal treatment. We focus on the irradiation regime where photochemical reactions occur, where weaker material modifications than those previously reported take place. In this regime, photochemistry can be performed since multiphoton ionization provides broad versatility by adapting the order of the absorption 
nonlinearity to the band gap of the considered material, as far as laser fluences and irradiances remain below the damage threshold. In Section 2, the mechanisms of energy deposition, structural relaxation and the different photo-ionization processes are briefly introduced for single pulse irradiation. In Section 3, the thermal and chemical diffusion processes taking place when cumulative pulses hit the material are presented. In Section 4, the different experimental configurations and parameters of fs laser structuring of these complex materials are discussed. In Section 5, the broad range of the physical properties that can be modified and the photochemistry involved in these changes are described. Finally in Section 6, possible applications with respect to the optical property changes are presented.

\section{Single pulse energy deposition and relaxation}

Traditionally, the dynamics of fs energy deposition is divided into three main steps, including the creation of free electrons through photo-ionization, their acceleration with absorption of other laser photons, and finally, additional release of free electrons through avalanche ionization when the kinetic energy of free carriers exceeds the material band gap energy.

\subsection{Multiphoton ionization and tunneling ionization}

Multiphoton ionization and tunneling ionization have been theoretically described by Keldysh in his well-known paper [64]. Multiphoton ionization of an atom is the simultaneous absorption of several photons with total energy exceeding the ionization potential of the electron energy level. Since the probability of multiphoton ionization is higher if the order is low, it is more favorable for short wavelengths. Tunneling ionization takes place when the incident electric field is sufficiently high to distort the potential barrier that maintains the electron in the field of the nucleus of an atom. The electron is then ejected by the tunneling effect through the lowered potential barrier. Since the distortion of potential barrier is dependent on the irradiance, tunneling ionization can only occur in the fs regime. The interaction between multiphoton ionization and tunneling ionization is complex and is generally quantified through the Keldysh parameter $\gamma$, which is the square root of the ratio between the electron ionization energy and the ponderomotive energy [64]. It is given by:

$$
\gamma=\sqrt{\frac{m_{e} c \varepsilon_{0} n_{0} E_{g} \omega_{L}^{2}}{e^{2} I}}
$$

where $\omega_{L}$ is the laser angular frequency, $m_{e}$ and $e$ the mass and the charge of the electron, respectively, $c$ the speed of light in vacuum, $n_{0}$ and $E_{\mathrm{g}}$ the RI and the band gap energy of the material, respectively, $\varepsilon_{0}$ the dielectric permittivity of vacuum and $I$ the irradiance. The competition between the two types of photo-ionization is delimited with $\gamma<1$ (i.e. for high irradiances) where tunneling ionization dominates, and with $\gamma>1$ (i.e. for low irradiances) where multiphoton ionization dominates.

\subsection{Avalanche ionization and multiphoton "forest fire" ionization}

Avalanche ionization is initiated by electrons with kinetic energy sufficient to ionize by collision a neighboring atom. By free carrier absorption, the new free electron will also gain kinetic energy and can then ionize similarly another neighboring atom. The characteristic time for avalanche ionization is $30-50 \mathrm{fs}$, requiring pulses longer than this time scale [65]. For shorter pulses, multiphoton "forest fires" ionization has been proposed as a substitute to avalanche ionization, taking place for intermediate values of the Keldysh parameter $(\gamma \geq 1)$ with the avalanche-like creation of holes in clusters or molecules [65-67].

\section{Multi-pulse cumulative thermal effects and chemical diffusion}

\subsection{Thermal effects}

Thermal effects in the focusing voxel are driven by the repetition rate of the laser [68-70]. The thermal diffusion relaxation time is determined by the thermal diffusion coefficient: 


$$
D_{t h}=\kappa / \rho_{0} C_{p},
$$

where $\kappa$ is the thermal conductivity, $\rho_{0}$ the density of the medium and $C_{p}$ the specific heat capacity at constant pressure. For a Gaussian beam with a beam waist $w_{0}$, the heat will evacuate the focusing voxel by diffusion in a time $\tau_{D}$ on the order of:

$$
\tau_{D} \approx w_{0}^{2} / 4 D_{t h} \text {. }
$$

In the particular case of pure fused silica, the thermal diffusivity is $D_{t h} \sim 8.4 \times 10^{-7} \mathrm{~m}^{2} . \mathrm{s}^{-1}$ [69]. For a beam waist of $w_{0}=2 \mu \mathrm{m}$, the corresponding diffusion time is $\tau_{D} \sim 1 \mu \mathrm{s}$. Thus, for multi-pulse after pulse cumulative thermal effects to occur, the repetition rate of the laser must be higher than $1 / \tau_{D}$, that is $1 \mathrm{MHz}$.

For material modification or breakdown to occur inside the material with a single fs pulse (or a series of pulses at a repetition rate lower than $1 / \tau_{D}$ ), the irradiance must be high enough to increase the temperature inside the focusing voxel to several hundreds or even thousands of degrees [63]. In that case, the photo-ionization and the thermal diffusion are clearly dissociated. The resulting changes are limited to that allowed by the thermodynamics processes, namely fusion and explosion.

For a series of fs pulses at a repetition rate higher than $1 / \tau_{D}$, heating of the material is achieved by cumulative pulse after pulse thermal effects, and therefore lower irradiances can be used to induce modifications inside the material. In that case, the same thermodynamics processes as for a single pulse can be addressed, but also photochemical processes, such as chemical reactions and phase transitions, thanks to a finer control and a broader range of interest on the irradiation couple \{fluence, temperature\}.

To predict the effects of cumulative heating during the laser irradiation, the heat diffusion equation with a source term corresponding to the absorbed laser energy must be solved:

$$
\frac{\partial T(\vec{r}, t)}{\partial t}-\nabla\left[D_{t h}(T) \times \vec{\nabla} T(\vec{r}, t)\right]=\frac{Q(\vec{r}, t)}{\rho_{0} C_{p}}
$$

where $T$ represents the temperature and $Q$ the heat source term. An analytical expression for the increase in temperature in this regime can be found [17,71-73]. Yet, to be realistic, the analytical expression must be addressed with measured experimental parameters such as the absorbed fraction of the laser energy, the nonlinear interaction volume, the temperature dependence of the thermal diffusivity and that of the heat source term.

For example, in a zinc phosphate glass containing silver, the temperature increases up to $375^{\circ} \mathrm{C}$ (below the glass transition temperature) for 10000 pulses at $10 \mathrm{MHz}$ repetition rate for a four-photon absorption process. This temperature enables the diffusion of the silver species without inducing any strong damage in the glass [17].

\subsection{Chemical diffusion}

When the temperature inside the focusing voxel reaches a few hundred degrees, chemical diffusion can be activated. The diffusion behavior of the activated species (atoms, ions or molecules) is described by the Fick's laws:

$$
\frac{\partial C_{i}(\vec{r}, t)}{\partial t}-\nabla\left[D_{i}(T) \times \vec{\nabla} C_{i}(\vec{r}, t)\right]=0,
$$

where $C_{i}$ is the concentration and $D_{i}$ the diffusion coefficient of the chemical species $i$, respectively. To solve this equation simply, the knowledge of the temperature dependence of the diffusion coefficient is required for each species.

Several works have been performed to investigate the ion exchange [74] and the related RI [75,76] or fluorescence [17,52] profiles inside the focusing voxel in glasses. Migration of different ions at the periphery of the focal point has been highlighted, resulting in a ringshaped structure. 


\subsection{Discussion}

The strong dependences of the diffusion coefficients raise another issue. It becomes clear that both Eqs. (4) and (5) are thus coupled equations that should be numerically solved simultaneously. Moreover, the diffusion of species within the glass or the polymer can be driven by a balance of effects that include concentration inhomogeneities and temperature gradients, depending on both the energy deposition per pulse and the associated repetition rate. These in turn determine the local temperature and therefore the chemical diffusion.

Two particular cases can be distinguished. When $\mathrm{T}>\mathrm{T}_{\mathrm{g}}$, the diffusion coefficient follows Einstein's relation $D_{i}(T)=\mu_{i}(T) k_{B} T$, where $\mu_{i}$ is the mobility of the species $i$ and $k_{B}$ the Boltzmann constant. Besides, it is directly proportional to the inverse of the glass viscosity which changes from several orders of magnitude between the room temperature and above the glass transition temperature [77]. When $\mathrm{T}<\mathrm{T}_{\mathrm{g}}$, the main mechanism for diffusion to occur is the hoping of the mobile species $\left(\mathrm{Na}^{+}, \mathrm{F}^{-}, \mathrm{Ag}^{+}, \mathrm{Ag}^{0}\right.$, etc...) from traps to traps (transient opened cages in the vibrating glass network) [78]. In this case, the diffusion coefficient depends on the temperature through the vibrating network, the vibration frequencies, the stabilization energy of the traps and the mass of the glass network formers. It has been showed that the addition of heavy ions, such as $\mathrm{Ca}^{2+}$, decreases the vibration frequencies and can lead to a decrease of the diffusion coefficient by up to two orders of magnitude [74]. The competition between two opposing effects - the trap vacancies and the mobile species concentration - influences also the behavior of the diffusion coefficient. To summarize, depending on the glass matrix, it is possible to activate the chemical diffusion of some mobile ions such as $\mathrm{Ag}^{+}$or $\mathrm{F}^{-}$, even below $\mathrm{T}_{\mathrm{g}}$. Therefore, by transport effects, the mobile species can be reorganized inside the glass matrix. For a perfect control of the diffusion process, specific temperature and diffusion coefficient measurement should be performed since the behavior is highly nonlinear with the temperature. For given laser processing time and material, an effective activation temperature $T_{a}$ for a particular species could be estimated.

\section{Experiment}

\subsection{Generic experimental setup}

The generic experimental setup for fs laser induced photochemistry is showed in Fig. 4. It is composed of a fs laser source; a device such as an acousto-optical modulator capable of controlling the pulse energy, the repetition rate and/or the number of pulses hitting the sample; a polarization control device; a focusing element such as a microscope objective; translation stages enabling the XYZ motion of the sample; and an imaging setup composed of a white light source and a camera.

\subsection{Influence of the experimental parameters}

Numerous experimental parameters are involved in fs laser structuring, depending mainly on the laser and, to a lesser extent, on the material. The parameters which determine the number of generated photo-electrons and the temperature inside the focusing voxel are listed below.

- Pulse energy: The pulse energy is the most important parameter. Together with the numerical aperture of the focusing element, it determines the fluence threshold for material modification as well as the number of generated photoelectrons.

- Pulse duration: The pulse duration, in the majority of the cases, is not critical as long as it remains $\leq 1 \mathrm{ps}$, the time necessary for heat to start to diffuse (electron-phonon coupling). Also, for avalanche ionization to occur, it must be higher than $50 \mathrm{fs}$ [65].

- Wavelength: The wavelength of the laser is associated with the band gap of the material and determines the order of multiphoton ionization. If the laser emits in the UV, since most materials have electronic resonances in this spectral region, the absorption will be linear ( $c f$. Fig. 1(a)). If the laser emits in the visible-NIR, depending on the cutoff wavelength of the material, multiphoton ionization can occur (cf. Fig. 1(b)). 
The ionization rate depends both on the laser wavelength and the material band gap [64].

- Repetition rate: The repetition rate of the laser plays a role in the thermal accumulation effects leading to a controlled increase of the temperature in the focal region [69]. For a given material, if it is lower than $1 / \tau_{\mathrm{D}}$, no multi-pulse cumulative effects take place. On the contrary, if it is higher than $1 / \tau_{\mathrm{D}}$, cumulative effects may occur, leading to a local increase of the temperature and to the diffusion activation of chemical species.

- Number of pulses / Writing speed: When cumulative effects are needed, the number of pulses influences the response of the material. When the material is moved, the writing speed $v$, associated to the repetition rate $R$ of the laser, determines the number of pulses $N$ hitting the sample in a given area and time. In the latter case, the number of pulses is given by $N=2 w_{0} R / v$, where $w_{0}$ is the beam waist.

- Polarization: The polarization of the beam is not critical in the majority of the resulting modifications, but nevertheless influences the interaction. For photo-ionization, the multiphoton ionization cross section is significantly higher for linear polarization than for circular polarization [79]. Concerning the photo-induced modifications, when the polarization is circular, the efficiency of laser-written waveguides is better by reducing the propagation losses on the laser-induced structure [80] or by limiting the nonlinear RI change during the writing process of waveguides [81]. The laserinduced reshaping of metallic NPs into non-spherical ones is also dependent on the polarization [82]. An opposite case is the creation of bulk "nanograting" structures, which can only be created with a linearly polarized beam [83].

- Numerical aperture: The numerical aperture $N A$ of the focusing element determines the size of the irradiated area, through the approximated relation $w_{0}=0.518 \lambda_{0} / N A$ (valid for $N A<0.7$ ) for a Gaussian beam [84], where $\lambda_{0}$ is the laser wavelength in vacuum. Together with the pulse energy, it determines the fluence threshold for material modification [85].

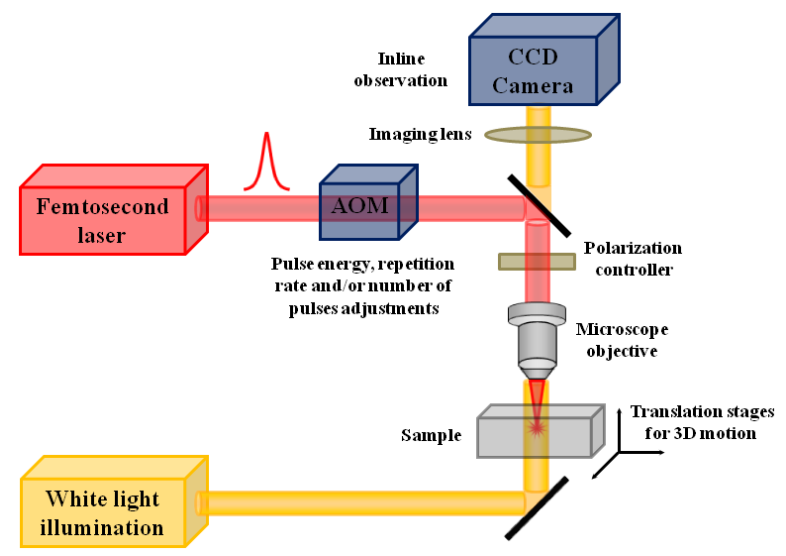

Fig. 4. Generic experimental setup for femtosecond laser structuring of transparent materials. AOM stands for Acousto-Optical Modulator.

\section{Laser activation of photochemical modifications}

The progression of the different photochemical reactions which can occur during light exposure and thermal treatment are depicted in Fig. 5. First, photo-ionization generates neutral atoms and color centers. Then nanoclusters, NPs and nanocrystallites can nucleate. 
Historically, Stookey used in a silver containing silicate glass a two-step process well separated in time with UV lamp irradiation for the reduction of the noble metal ions (latent image) followed by a thermal treatment for the production of NPs (developed image) [26]. Modern laser-irradiation tends to directly initiate the development of the latent image, due to the laser energy deposition from multiphoton ionization and pulse heating.

\subsection{Color centers and valence state manipulation}

A color center is a point lattice defect consisting of a vacant negative ion site and an electron bound to the site. Such defects will absorb light and make certain normally transparent materials appear colored. Laser irradiation can lead to moderate local rearrangements of charges inside the material, associated to a laser-induced modification of the valence state of active ions, forming color centers. They can be associated with both active ions such as metal ions as well as rare earth ions. To create a color center, the required irradiation conditions need only to be sufficient to photo-activate oxidation-reduction chemical reactions through the generation of photoelectrons in the irradiated area following the generic relations: $\mathrm{h} v+\mathrm{A}^{\mathrm{n}+} \rightarrow$ $\mathrm{A}^{(\mathrm{n}+1)+}+\mathrm{e}^{-} ; \mathrm{B}^{\mathrm{p}+}+\mathrm{e}^{-} \rightarrow \mathrm{B}^{(\mathrm{p}-1)+}$. Here, thermal activation and heat accumulation are not required since the only laser-induced matter motion is the rearrangement of the charges with electron/hole motions in laser-induced oxidation-reduction reactions. These irradiations are related to low repetition rates of $1 \mathrm{kHz}$, preventing significant ion mobility and most likely only allowing valence state modifications and electron-hole movements. Laser-induced color centers exhibit changes of absorption and emission properties with respect to the matrix. They normally exhibit a limited thermal stability because of their low activation energy, and thus can easily be annealed [30]. Some however are stable almost up to the glass temperature transition $\mathrm{T}_{\mathrm{g}}$, which is interesting for applications $[35,86]$.

Different types of color centers from metal transition elements have been reported, such as noble metal reduction [26,30], or the $\mathrm{Mn}^{2+}$ ion oxidation coupled to the $\mathrm{Fe}^{3+}$ ion reduction in $\mathrm{Mn} / \mathrm{Fe}$ co-doped glass, leading to broadband absorption modifications and colored images $[35,86]$. Other types of color centers have been observed with the reduction of the valence state of rare earth ions such as $\mathrm{Eu}^{3+}$ to $\mathrm{Eu}^{2+}$, or $\mathrm{Sm}^{3+}$ to $\mathrm{Sm}^{2+}$, providing significant spectroscopic modifications in both absorption and emission bands [35,51].

These color centers show a sufficient stability at room temperature for applications such as optical data storage. Such color centers are rather stable traps, associated to significantly deep potential traps. However, they can generally be erased with a soft thermal treatment below $\mathrm{T}_{\mathrm{g}}$, without the additional growth of particles [30,35,51]. The temperature increase can be performed either by external heating or with laser irradiation $[33,51]$.

\subsection{Nanoclusters}

Nanoclusters are molecular entities composed of a few atoms that are too small to support a plasmon resonance but still possess remarkable fluorescence properties [87]. The production of nanoclusters in glasses by fs laser irradiation involves two steps: (1) the generation a latent image composed of neutral atoms from photo-ionization and (2) the aggregation of active ions and neutral atoms from thermal activation, when the mobility of the species is sufficient for hoping diffusion [78,88] ( $c f$. Section 3 and Fig. 5). Various metallic (Ag, Au, etc...) nanoclusters in different matrices have been widely studied, but this section focuses only on silver nanoclusters in glass, zeolite and polymer matrices.

Nanoclusters in glasses

In phosphate silver containing glasses, fs laser irradiation provides both photo-ionization and heating for silver nanocluster formation. This has been widely reported for both low [36-41] and high $[17,19,23,42-44]$ repetition rate exposures. Small clusters, with less than three silver entities, appear to be preponderant at low repetition rate [36-41], while larger $\mathrm{Ag}_{\mathrm{m}}{ }^{\mathrm{x}}$ lowcharged clusters (with $\mathrm{m}<10$ and a low $\mathrm{x} / \mathrm{m}$ ratio) are created at higher repetition rate $[17,19,23,42-44]$. These studies have demonstrated the direct influence of the repetition rate on cumulative heating effects, leading to a more efficient diffusion and the growth of larger 
clusters. Additional evidence has been supplied by systematic investigation of the influence of the repetition rate (from $100 \mathrm{kHz}$ to $10 \mathrm{MHz}$ ) on the fluorescence response of laser-induced silver clusters [44]. Nanocluster production is partial and very limited for low repetition rate systems, from a few $\mathrm{Hz}$ and below $200 \mathrm{kHz}$ [36-41,89], while it tends to be much more advanced for high repetition rate systems, at the $\mathrm{MHz}$ range [17,19,23,42-44].

The larger $\mathrm{Ag}_{\mathrm{m}}{ }^{\mathrm{x}}$ nanoclusters revealed thermal stability below $300^{\circ} \mathrm{C}$ in a phosphate glass matrix [17], contrary to the small clusters, $\mathrm{Ag}^{0}$ atoms [42] or color centers which were annealed below $300^{\circ} \mathrm{C}$ [30]. The formation of these $\mathrm{Ag}_{\mathrm{m}}{ }^{\mathrm{x}}$ clusters provides a promising approach for perennial multi-level encoding high density optical data storage [19].

In silicate glass, the number of silver clusters was increased with optimal thermal treatment at $300^{\circ} \mathrm{C}$. At higher temperatures, silver clusters tended to change into NPs, leading to the decrease of the luminescence intensity [89]. In addition, these studies in phosphate and silicate glasses provide evidence that nonlinear photo-ionization processes and thermal effects can be decoupled to a certain point, with multiphoton ionization controlled by the laser irradiance, and the trapped charge redistribution and cluster formation controlled by the repetition rate [44].

Nanoclusters in zeolite crystals and in polymers

Zeolites are inorganic microporous crystals close in formation to alumino-silicate composition. They can stabilize small silver ions by preventing cluster growth because of steric reasons in the microporous cages [47]. The same laser-irradiation scheme of Ag-loaded zeolites can promote silver reduction. The growth of silver clusters is then driven by photoinduced processes or by purely thermal activation $[48,49]$. Contrary to glass matrices, silvers clusters are located in micropores, opening the practical application of optical encoding [18].

Photo-activation of polymers with silver ions has also been reported with irradiation from an $87 \mathrm{MHz}$ fs Ti:Sa source. Small silver clusters were assumed to form on pre-existing silver oxides, resulting from photo-activation through direct photo-induced electronic excitation, without the need of thermal activation even though slight temperature increase might facilitate the mobility of the silver atomic compound [45]. Silver cluster photo-activation could occur both at the surface and within biopolymers [45,46].

To summarize, some $\mathrm{Ag}_{\mathrm{m}}{ }^{\mathrm{x}+}$ nanoclusters present a better thermal stability up to the glass transition temperature. Large nanoclusters show less diffusivity due to their size. These two features allow the nanoclusters to be nucleation centers for the further growth of metallic NPs or nanocrystallites.

\subsection{Laser-activated phase transitions into nanoparticles}

After the production of a latent image, as described in Sections 5.1 and 5.2, metallic NP growth can be obtained with a post-irradiation heat treatment. These NPs can also be obtained with direct laser irradiation, by controlling the temperature increase with energy deposition and laser repetition rate [46]. Whatever the chosen approach to form metallic NPs, a sufficiently high temperature, around or above $T_{g}$ (higher than the activation temperature $T_{a}$ of metal atom mobility), is required to afford the matrix network rearrangement. NPs are suspected to nucleate on stable clusters at such high temperatures, acting as nucleation centers. Depending on the thermodynamics, the heat treatment and the availability of metal elements and other chemical species, new phases can grow such as NPs, crystalline phases, or even both.

Laser-induced metallic nanoparticles

Growth of NPs after laser-activation was evidenced in many glasses [17,90,91], with or without additional optical sensitizer such as $\mathrm{Ce}^{3+}$ ions [31,50], in noble metal doped glasses with silver [29,92-94] or gold [30,95] or even both [96].

In such works, the required temperature to grow metallic NPs during post-irradiation heat treatment is much lower in the laser-modified areas than elsewhere [95]. This differential 
behavior originates from the localization of nucleation germs at the location of the latent image only, providing a spatial selectivity in the precipitation of metallic NPs.

Different glass compositions, with specific doping concentrations and types lead to a large panel of thermal response as well as different behaviors for mobility activation of species $[31,93,97]$. Such diversity in materials is the cause of the broad variety of heat treatment sequences which are reported close or above $\mathrm{T}_{\mathrm{g}}$. The large panel of heat treatment, as well as irradiation parameters, therefore affords a true selectivity in the size and concentration of NPs during their growth. This allows a significant control of optical properties such as plasmon resonance amplitude and spectral position [30,93-96]. It also allows the control of metal selectivity of NP precipitation for co-doped glasses, emphasizing on the different mobility between silver and gold species [96]. Additional heat treatment may even lead to the subsequent dissolution of NPs.

Direct formation of metallic NPs was also reported without requiring the usual postirradiation heat treatment. Silver NPs were generated in irradiated silicate glasses [76] and gelatin polymers [46], with $250 \mathrm{kHz}$ and $87 \mathrm{MHz}$ repetition rate lasers, respectively.

Laser-modified nanoparticles

Composite glasses with embedded spherical metallic NPs have shown significant laserinduced modifications, leading to the permanent deformation and asphericity of the NPs. The related mechanism was described by the ejection of electrons along the laser polarization, the expulsion of $\mathrm{Ag}^{+}$ions [88] or even $\mathrm{Ag}_{\mathrm{m}}{ }^{\mathrm{X}}$ small nanoclusters [28], and the subsequent recombination of $\mathrm{Ag}^{0}$ mobile species with the original $\mathrm{NP}$ along the laser polarization direction [98-100].

The optical response of the reshaped particles depends on their environment, size and volume fraction [101]. It generally results in a red-shifted plasmon resonance for the pcomponent and a blue-shifted one for the s-component, respectively along the long and the short axes of the reshaped particle [21,53,101-104]. As for the NP nucleation and growth, NP deformation is strongly dependent on the laser fluence and dose, as well as on the local temperature. Indeed, a weak global temperature increase of the glass matrix could limit the anisotropic reshaping of the NPs or even lead to their dissolution [15,56,105], providing shaping reversibility for heat treatment above the glass transition temperature.

Another original approach was developed with the irradiation of dispersed multi-ratio gold nanorods, which showed both polarization and wavelength sensitivity thanks to the addressed orientation and the shape ratio during the photo-thermal patterning. Selective plasmon resonance absorption afforded the thermal reshaping of selected nanorods into spherical particles, providing an innovating support for multi-dimensional optical recording [16].

Laser-activated phase transition into dielectric nanocrystallites

As with metallic NPs, the growth of nanocrystallites needs nucleation centers, the existence of a thermodynamically more stable phase, and a sufficient mobility of the involved species. The growth of nanocrystallites therefore requires a heat treatment above the glass transition temperature to afford sufficient glass matrix rearrangements.

Laser-activation growth of crystallites has been reported in several glasses doped with $\mathrm{Ag}^{+}$ ions [14,20,27,32,106], $\mathrm{Er}^{3+}$ ions [107], or $\mathrm{Ti}^{3+}$ ions [22]. The large variety of reported thermal treatments corresponds to the broad diversity of glass compositions and irradiation conditions, and implies that glass properties partially keep the memory of the temperature evolution [68].

At low repetition rate and subsequent heat treatment, cubic NaF nanocrystallites grew from silver colloids acting as crystallization nuclei [27]. The involved elements, $\mathrm{Na}$ and F, are small and highly mobile, enabling them to act as efficient glass network modifiers inside the initial glass network [75]. In some cases, both NaF crystallites and silver metallic NPs could simultaneously be observed after heat treatment [14], for a large variety of irradiation conditions. Lithium metasilicate nanocrystallites [32] and other nanocrystallites $[106,108]$ were also produced with a similar approach. 
At high-enough repetition rates (above $200 \mathrm{kHz}$ ), laser irradiation can provide the thermal source for the particle growth from the nucleation centers in the photo-activated zones, since accumulation effects can largely exceed the temperature $T_{g}$. Strong laser-induced modifications provided crystallization centers which seeded the growth of $\beta-\mathrm{BaB}_{2} \mathrm{O}_{4}(\mathrm{BBO})$ crystallites with subsequent laser heat of the previously melted spot $[20,109]$. Elsewhere, $\mathrm{Er}^{3+}-$ doped $\mathrm{CaF}_{2}$ nanocrystallites were formed after strong local heating above $2000{ }^{\circ} \mathrm{K}$ [107]. The crystalline phase $\mathrm{Sr}_{2} \mathrm{TiSi}_{2} \mathrm{O}_{8}$ was also directly obtained after irradiation at $200 \mathrm{kHz}$ without additional heat treatment [22].

\subsection{Discussion}

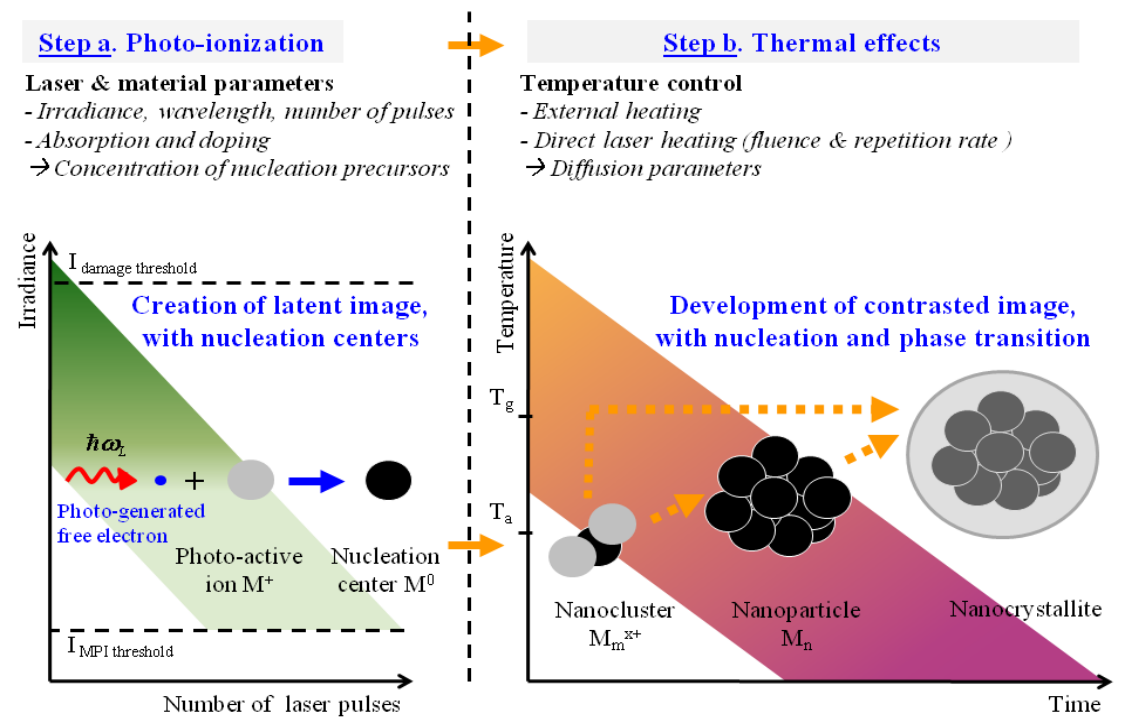

Fig. 5. Different steps leading to the formation of nanoclusters, NPs and nanocrystallites. Once nucleation centers are formed from photo-ionization, nanoclusters, NPs and nanocrystallites grow as the temperature of the thermal treatment increases. $\mathrm{T}_{\mathrm{a}}$ is the activation temperature and $\mathrm{T}_{\mathrm{g}}$ is the glass transition temperature. MPI stands for multiphoton ionization.

Much of this discussion focuses on the role of the temperature in the different chemical reactions occurring during or after laser irradiation through the model case of a sodiumsilicate glass matrix containing a sensitizer ion such as $\mathrm{Ce}^{3+}$ and a photosensitive ion such as $\mathrm{Ag}^{+}$. From all the above observations, the photo-ionization processes for the formation of color centers and nanoclusters is well understood, whereas the role of the temperature to create NPs or nanocrystallites is not as clear. Concerning the photo-ionization processes, the seed of free electrons comes from the sensitizer $\left(\mathrm{Ce}^{3+} \rightarrow \mathrm{Ce}^{4+}+\mathrm{e}^{-}\right)$for UV irradiation [14] and from the photosensitive agent $\left(\mathrm{Ag}^{+} \rightarrow \mathrm{Ag}^{2+}+\mathrm{e}^{-}\right)$or the glass matrix $\left(\mathrm{M} \rightarrow \mathrm{M}^{+}+\mathrm{e}^{-}\right)$for fs laser irradiation $[14,27] . \mathrm{Ag}^{2+}$ color centers are thus created as well as $\mathrm{Ag}^{0}$ neutral atoms, through the reaction $\mathrm{Ag}^{+}+\mathrm{e}^{-} \rightarrow \mathrm{Ag}^{0}$. The temperature increase during the laser exposure above the activation temperature $\mathrm{T}_{\mathrm{a}}$, typically around $200-300^{\circ} \mathrm{C}$, allows either the $\mathrm{Ag}^{+}$ions or the $\mathrm{Ag}^{0}$ neutral atoms to diffuse in a rigid glass network and to aggregate into $\mathrm{Ag}_{\mathrm{m}}{ }^{\mathrm{x}+}$ small nanoclusters ( $c f$. Fig. 5). The initial concentration and chemical diffusivity of $\mathrm{Ag}^{+}$ions is a key parameter for the aggregation of silver $\mathrm{Ag}_{\mathrm{m}}{ }^{\mathrm{x}}$ nanoclusters. Besides, the addition of heavy ions, such as $\mathrm{Ca}^{2+}$, can lead to a decrease of the diffusion coefficient up to two orders of magnitude [74]. It is therefore obvious that it is easier to form nanoclusters if both the initial concentration and diffusivity of $\mathrm{Ag}^{+}$ions are high.

When additional heat treatment above the glass transition temperature is performed, the diffusivity of small ions such as $\mathrm{Na}^{+}, \mathrm{F}^{-}$and $\mathrm{Ag}^{+}$ions or neutral atoms as $\mathrm{Ag}^{0}$ increases drastically. As a consequence, $\mathrm{NaF}$ nanocrystallites can be formed either directly or through 
$\mathrm{Ag}_{\mathrm{n}}$ NPs ( $c f$. Fig. 5). It is not clear if NPs are necessary to form nanocrystallites, or if these latter can be nucleated directly from nanoclusters [14,27].

The nucleation of the species composing the crystal ( $\mathrm{Na}^{+}$and $\mathrm{F}^{-}$ions) occurs around $\mathrm{T}_{\mathrm{g}}$, because the matrix is more malleable at this temperature. As a consequence, these species can rearrange into nanocrystallites.

\section{Optical property changes, photochemical reactions and applications}

As showed in the previous section, many photochemical reactions can occur when a photosensitive material is exposed to fs laser irradiation followed or not by a thermal treatment. Nevertheless, for an application in view, some photochemical reactions and associated optical property changes are more suitable. Table 1 summarizes the desired optical property changes, the associated photochemical reactions and the possible applications.

Table 1. Summary of the Desired Optical Property Changes, the Associated fs LaserInduced Photochemical Reactions and the Possible Applications

\begin{tabular}{|c|c|c|c|}
\hline Optical property change & Photochemical reaction & Application & Reference \\
\hline Linear refractive index & $\begin{array}{c}\text { Laser-induced NPs } \\
\text { Laser-modified NPs } \\
\text { Nanocrystallites }\end{array}$ & $\begin{array}{c}\text { Optical grating, optical switching } \\
\text { Optical grating, micro-polarizer, } \\
\text { filter, display, optical recording } \\
\text { Waveguide, optical recording, } \\
\text { volume holography }\end{array}$ & $\begin{array}{c}{[31,35]} \\
{[15]} \\
{[14,35,106,107]}\end{array}$ \\
\hline $\begin{array}{c}\text { Plasmon resonance } \\
\text { (absorption) }\end{array}$ & Laser-modified NPs & Optical recording & {$[15,16]$} \\
\hline Luminescence & Nanoclusters & Optical recording & {$[18,19]$} \\
\hline $\begin{array}{c}\text { Second-order } \\
\text { susceptibility } \chi^{(2)}\end{array}$ & $\begin{array}{c}\text { Nanocrystallites } \\
\text { Nanoclusters }\end{array}$ & Frequency conversion & {$[20,22]$} \\
\hline $\begin{array}{c}\text { Third-order susceptibility } \\
\chi^{(3)}\end{array}$ & Nanoclusters & Optical recording & {$[23]$} \\
\hline Preferential dissolution & Nanocrystallites & $\begin{array}{c}\text { Micro-fluidics, integrated micro- } \\
\text { optics }\end{array}$ & {$[27,32,50]$} \\
\hline
\end{tabular}

\section{Conclusion}

This review summarizes the progress made in recent years in understanding the complex photochemical processes that can be induced by high intensity laser light in bulk transparent glasses and polymers that have been specifically tailored with photo-active agents. By bringing together an assessment of the various physical and photochemical processes involved and a summary of the optical and chemical effects so far observed, it sets the stage for a rapid evolution in the uses and applications of this new mode of laser-written structural engineering of microscopic systems in these media.

This study demonstrates the importance that temperature plays in the re-assembly of metallic ion and atom constituents in these materials, both during the laser irradiation process itself and following it, either directly, or indirectly through annealing. It introduces a new control parameter determining the final state and purpose of the material. Even though we are at an early stage in exploiting the new capabilities opened up by laser irradiation of photoactive media, the identification and enunciation of the photo-chemical effects so far observed opens many new doors of investigation. The formation or manipulation of color centers, nanoclusters, nanoparticles, nanocrystallites and other physico-chemical changes in the medium through the microscopic deposition of laser energy offers the opportunity to restructure the optical properties of these materials in a deterministic manner with very high spatial precision. As more ultrafast laser sources become available, at different wavelengths, with different pulse regimes, we will learn still more the potential of these new capabilities.

The new capabilities summarized in this review will add to the general understanding of ultra-fast laser-induced effects that can be created in transparent media. As this field matures, and many of these effects are incorporated into multi-functional devices, where particularly the three-dimensional structuring can be exploited in integrated systems, the importance of the laser-induced photo-chemical effects summarized here will increase. 


\section{Acknowledgments}

The authors acknowledge the Conseil Régional d'Aquitaine, the GIS AMA and the ANR (grant \# BLAN 946 04) for their financial support and Thierry Cardinal from the ICMCB for helpful discussions.

\#151054 - \$15.00 USD Received 13 Jul 2011; revised 28 Jul 2011; accepted 28 Jul 2011; published 8 Aug 2011

(C) 2011 OSA 1 September 2011 / Vol. 1, No. 5 / OPTICAL MATERIALS EXPRESS 882 